\title{
Alkali Treatment of Screw Pine (Pandanus Odoratissimus) Fibers and Its Effect on Unsaturated Polyester Composites
}

\author{
Hairul Abral $^{1}$, M. Fitra Gafar ${ }^{1}$, Heri Andriyanto', Ilhamdi ${ }^{1}$, S. M. Sapuan², \\ M. R. Ishak ${ }^{2}$, and Evitayani ${ }^{3}$ \\ ${ }^{1}$ Department of Mechanical Engineering, Andalas University, Padang, Sumatera Barat, Indonesia \\ ${ }^{2}$ Department of Mechanical and Manufacturing Engineering, Universiti Putra Malaysia, Serdang, \\ Selangor, Malaysia \\ ${ }^{3}$ Department of Animal Science, Andalas University, Padang, Sumatera Barat, Indonesia
}

\begin{abstract}
Characteristics of Screw Pine fiber of species Pandanus Odoratissimus ( $P$ O fibers) and short $\mathrm{PO}$ fibers reinforced composite were studied. The results show that various alkali concentrations changed ability of PO fibers in absorptions of moisture, chemical compositions and cross-sectional area. The untreated and treated PO fibers were compounded with unsaturated polyester to evaluate their mechanical properties. The treated PO fiber composites exhibit high mechanical properties in comparison with untreated ones. SEM photographs revealed a different fracture surface between untreated PO fiber-reinforced composites and treated ones.
\end{abstract}

Keywords Alkali treatment; Mechanical properties; Screw Pine fibers

\section{INTRODUCTION}

Earth provides a source of plentiful natural fibers in many forms and types that have great potential to be applied as reinforcements for composites. Several natural fibers that have been investigated intensively come from $\operatorname{coir}^{[1]}$, Jute ${ }^{[2]}$, abaca ${ }^{[3]}$, arenga pinnata fiber ${ }^{[4]}$, sago palm ${ }^{[5]}$, etc. One of the potential cellulosic fibers to be used in material reinforcement, especially in polymer composites is screw pine plant Pandanus Odoratissimus (PO) that belongs to the Pandanaceae family ${ }^{[6]}$.

This plant is very abundant, found widely in wild tropical forests as in West Sumatera, Indonesia. A unique characteristic of screw pine trees is that it has long, green leaves with many thorns on the edges of leaf. Growing the plant does not require special treatment in fertilization. However, abundant sources of PO leaves that are used for commercial products are limited.

PO leaves seem to have excellent properties because they have been widely used to make traditional products, compared to pineapple leaves. Some kinds of traditional

Address correspondence to Hairul Abral, Department of Mechanical Engineering, Andalas University, Padang, Indonesia. E-mail: abral@ft.unand.ac.id products that apply the screw pine leaves are mats, baskets (including for ladies and to keep valuables), hats, fans, pillows, canoe sails, toys, and other plaited wares.

To make traditional products, the green leaves of the umbrella tree should be boiled for several hours to increase their toughness, and then they are dried with sun light. After such treatment, the brown-colored PO leaves are ready to be applied to produce the traditional components. Indeed, a PO leaf as cellulosic crop has more fibers that can be used to reinforce polymer composites. However, investigations of PO fiber-reinforced polymer composites are still limited.

Thus, it is very interesting to study characteristics of the PO fibers compounded by unsaturated polyester resin because such resin is used more widely in modern products. It is well known that cellulosic fibers are generally incompatible with polymers due to their hydrophilic nature ${ }^{[7]}$. To improve the compatibility, many physical and chemical treatments have been developed to overcome this problem ${ }^{[8,9]}$. One of the usual treatments for enhancing compatibility is an alkalization method using sodium hydroxide $(\mathrm{NaOH})^{[9,10]}$.

Therefore, the objective of this article is to present the characteristics of PO fibers treated with sodium hydroxide solution in various alkali concentrations. PO fiber characteristics measured are moisture absorption ability, crosssectional area and chemical compositions. Then, the cellulosic PO fibers in untreated and treated states are mixed with unsaturated polyesters to produce composites, and the mechanical properties are measured.

\section{METHODS}

\section{Material Source}

Material sources of PO fiber were taken from leaves of umbrella trees growing in the wild forest in West Sumatera, Indonesia (Fig. 1a). Steps that were conducted to extract PO fibers from their leaves have been shown in Figures 1b-1f. The PO leaves in nature have more thorns, which were 